NASA Technical Memorandum 106468

\title{
Measurements and Modeling of Flow Structure in the Wake of a Low Profile "Wishbone" Vortex Generator
}

B.J. Wendt and W.R. Hingst

Lewis Research Center

Cleveland, Ohio

Prepared for the

AIAA 32nd Aerospace Sciences Meeting and Exhibit

sponsored by the American Institute of Aeronautics and Astronautics

Reno, Nevada, January 10-13, 1994 
? 


\title{
Measurements and Modeling of Flow Structure in the Wake of a Low Profile "Wishbone" Vortex Generator
}

\author{
B.J. Wendt* and W.R. Hingst \\ Lewis Research Center \\ Cleveland, Ohio 44135
}

\begin{abstract}
The results of an experimental examination of the vortex structures shed from a low profile "wishbone" generator are presented. The vortex generator height relative to the turbulent boundary layer was varied by testing two differently sized models. Measurements of the mean three-dimensional velocity field were conducted in crossstream planes downstream of the vortex generators. In all cases a counter-rotating vortex pair was observed. Individual vortices were characterized by three descriptors derived from the velocity data; circulation, peak vorticity, and cross-stream location of peak vorticity. Measurements in the crossplane at two axial locations behind the smaller wishbone characterize the downstream development of the vortex pairs. A single region of streamwise velocity deficit is shared by both vortex cores. This is in contrast to conventional generators, where each core coincides with a region of velocity deficit.

The measured cross-stream velocities for each case are compared to an Oseen model with matching descriptors. The best comparison occurs with the data from the larger wishbone.
\end{abstract}

\section{Background and Research Objectives}

Vortex generators are used to provide a measure of flow control. Most often the goal is to achieve some resistance to boundary layer separation or to reduce the deleterious effects of locally strong secondary flows.

In external flow situations, such as that encountered on airfoils, the most common application is upstream of flight control surfaces where boundary layer attachment is often critical to flight performance.

In internal flows vortex generators are used to prevent flow separation and reduce total pressure distortion. These effects occur often in inlet ducts and diffusers, due to such factors as duct centerline curvature and large changes in duct cross-sectional area.

Copyright 1993 by the American Institute of Aeronautics and Astronautics, Inc. No copyright is asserted in the

United States under Title 17, U.S. Code. The U.S. Government has a royalty-free license to exercise all rights under the copyright claimed herein for Governmental purposes. All other rights are reserved by the copyright owner.

\footnotetext{
* National Research Council-NASA Research Associate at Lewis Research Center.
}

The key to vortex generator performance is in the mixing and secondary velocity field created downstream by the shed vortex structures. If properly situated in the flow field, the helical motion of the fluid in the vortex forces high energy fluid of the freestream into the slower moving fluid of the boundary layer while countering the tendency of naturally occurring secondary flows to distort the flow field by the opposite mechanism, namely to displace boundary layer fluid away from the wall and into core regions of the flow.

Since the vortex generator presents an obstruction in the flow, there is a drag penalty paid for its use. Conventional blade type or delta wing type vortex generators are found to work best when the vortex generator height above the flow surface, $h$, is approximately that of the local boundary layer thickness, $\delta$. Recent work in the design and performance of vortex generators has produced low profile vortex generators that meet or exceed the mixing and strength performance of more conventional types. The height ratio, $h / \delta$, for a low profile vortex generator is typically between one and three-tenths, thereby providing a substantial reduction in the drag penalty paid for its use. Low profile vortex generators have been used recently to improve the high angle of attack behavior of missiles, ${ }^{1}$ control a shock-boundary layer interaction, ${ }^{2}$ and improve the total pressure distortion and recovery performance of a diffusing S-duct. ${ }^{3}$ Figure 1 illustrates the use of a "wishbone" generator, which is a particularly effective low profile design. The secondary velocity

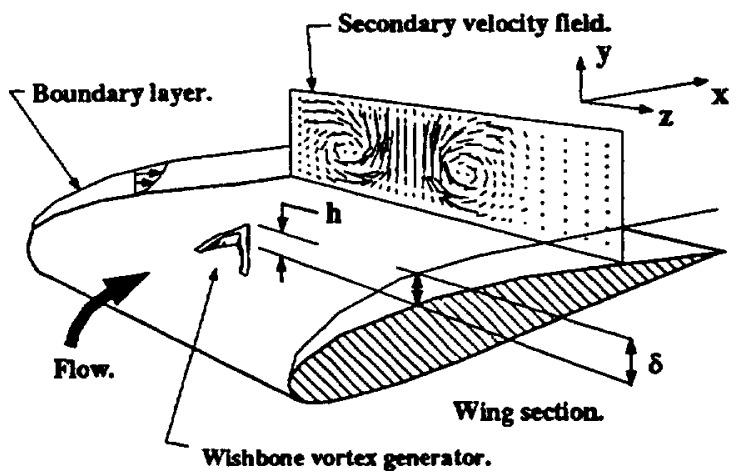

Figure 1 The flow structures shed from a vortex generator are examined in a downstream crossplane.

structure of the shed vortices is measured in a crossplane downstream of the vortex generator. As indicated in Figure 1 , this structure is a pair of counter-rotating vortices with the flow between vortices directed away from the wall (an "upflow" pair). This structure was verified in a flow visualization study conducted by Lin $e t a .^{4}$ 
Our qualitative description of embedded vortex structure can be quantified using three parameters or "descriptors". For any embedded vortex $i$ these are:

1. $\left(z_{i}, y_{i}\right)$ - Location of the vortex core center. Its variation with axial position $x$ represents the trajectory of the vortex.

2. $\omega_{i}^{\max }-$ Peak vorticity. The peak vorticity is located at $\left(z_{i}, y_{i}\right)$ and its magnitude is indicative of the vortex concentration.

3. $\Gamma_{i}-$ Circulation of the vortex. $\Gamma_{i}$ represents the "spinning strength" of the vortex.

Each of these three descriptors are derivable from the secondary velocity data taken in a downstream crossplane, as illustrated in Figure 1. A recent study conducted at NASA Lewis Research Center ${ }^{5}$ focused on the quantitative description of the vortices shed from conventional vortex generator blades. In this study we conduct a similar examination of the low profile wishbone generator. The objectives of this study are summarized as follows:

1. Mount a large low profile wishbone generator in the thick boundary layer of NASA Lewis Research Center's Icing Research Tunnel (IRT). At a suitable position downstream of the vortex generator conduct highly resolved crossplane velocity surveys to characterize and quantify the vortex structures produced by the generator. Conduct these measurements on two different models, varying $h / \delta$. For one model, examine two downstream crossplanes to study the streamwise development of these structures.

2. These measurements have the additional benefit of providing workers in computational fluid dynamics a basis for modeling low profile wishbone generators in their studies. Simple mathematical models, developed in terms of the vortex descriptors, are derived from the data to represent the measured vortex structures as velocity and vorticity distributions. These models are then compared against the data.

\section{Facilities and Procedures}

The Test Facility

The investigation of tip vortices shed from vortex generators generally involves a grid spacing having a scale similar to that of the vortex viscous core diameter. In the near-wake region of a low profile vortex generator this is roughly the same size as $h$, and thus only a fraction of the local boundary layer thickness. Typical test section turbulent boundary layers generated in facilities at NASA-Lewis are on the order of a centimeter or so in thickness. To obtain the fine scale grid resolution desired for this study it was necessary to locate a test facility capable of generating a nominally two-dimensional turbulent boundary layer with $\delta$ in excess of 7 or 8 centimeters. This requirement was determined as a result of balancing

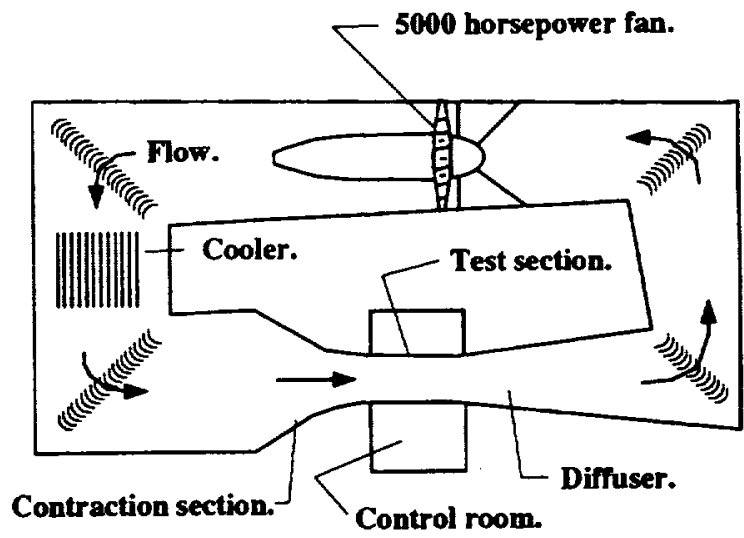

Figure 2 A schematic illustration of NASA Lewis' Icing Research Tunnel.

such factors as time available for testing and the size of five-hole probe tips available for use within Lewis' Inlets, Ducts, and Nozzles workgroup. NASA Lewis Research Center's IRT is a suitable candidate, having a turbulent test section wall boundary layer of the required thickness. The IRT is a large subsonic test facility designed and equipped to support the testing of low speed models. It is a closed-return atmospheric-type tunnel with a rectangular cross-section at every axial station. Figure 2 is a plan view of the IRT showing its various operational elements. In this study tunnel total pressure and total temperature are approximately atmospheric. The test section dimensions are 1.8 by 2.7 meters with velocities ranging between 20 and 140 meters/sec. Corresponding mass flow rates are between 100 and 500 kilograms $/ \mathrm{sec}$.

Operation of the wind tunnel is fully automatic. Pressure and temperature instrumentation located in the test section provides the data input to aid in setting and controlling tunnel flow conditions. Each flow measuring device, whether operational or research, is monitored by a central minicomputer based operating system.

More information concerning the design, operations, and capabilities of the IRT may be found in the report of R. Soeder and C. Andracchio. ${ }^{6}$

Test Parameters and Research Instrumentation

Figure 3 is an illustration of the test section showing the coordinate system in use. The cartesian coordinate axes are centered on the tunnel top wall at an axial location corresponding to the boundary between the contraction and test section. The model vortex generator, probe, and probe traversing hardware are mounted on a hatch in the test section ceiling. The leading edge of this hatch is located at $x \approx 3$ meters. This test was conducted at a freestream Mach number of 0.2 . The test section freestream velocity, $U_{\infty}$, is approximately 70 meters $/ \mathrm{sec}$.

Boundary layer surveys conducted in the empty test section indicate a nominally two-dimensional turbulent profile over the central two-thirds span of the top wall. At the axial location corresponding to the mounting position 


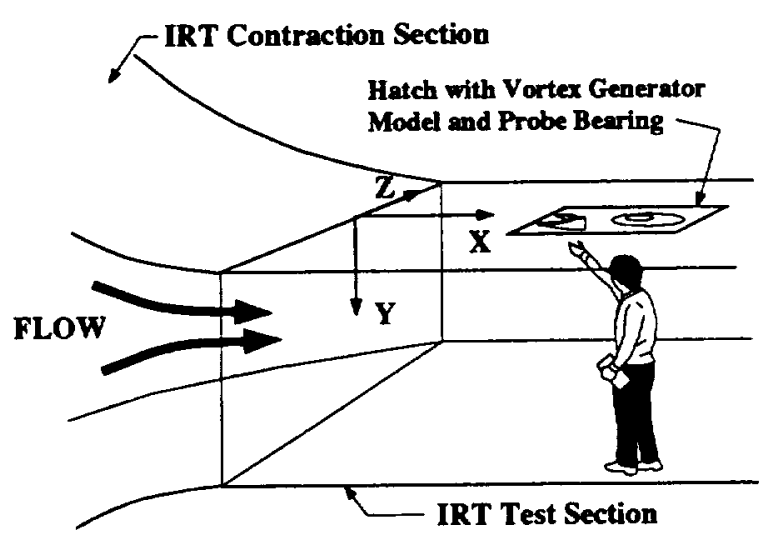

Figure 3 The IRT test section showing the coordinate system used and the location of the test hardware.

of the vortex generator model $\delta \approx 9$ centimeters, and the Reynolds number is $R e=U_{\infty} x / \nu \approx 13 \times 10^{6}$. No significant spanwise variations in profile shape or thickness were detected in the center span region of the test section ceiling.

The vortex generator models tested in this study are patterned after the Wheeler wishbone design. ${ }^{7}$ Figure 4 is an illustration of the geometry. Two models were constructed from a block of aluminum alloy using a wire cutting (EDM) process. The dimensions of both models are given in Figure 4.

Figure 5 illustrates the arrangement of hatch, vortex generator model, velocity probe, and traversing bearing. A two axis $(z, y)$ mechanism located above the hatch moves the probe stem in the crossplane survey grid, sealed by the free-floating "double-bearing" rig.

The velocity probe is a five-hole Pitot probe with a tip diameter of $0.23 \mathrm{cms}$. This probe tip is mounted off-axis on a goose-necked stem to a position upstream of the circular bearing seal line. The probe is used in a non-nulling capacity and is calibrated to determine all three components of the mean flow velocity following the procedure outlined by Treaster and Yokum. ${ }^{8}$

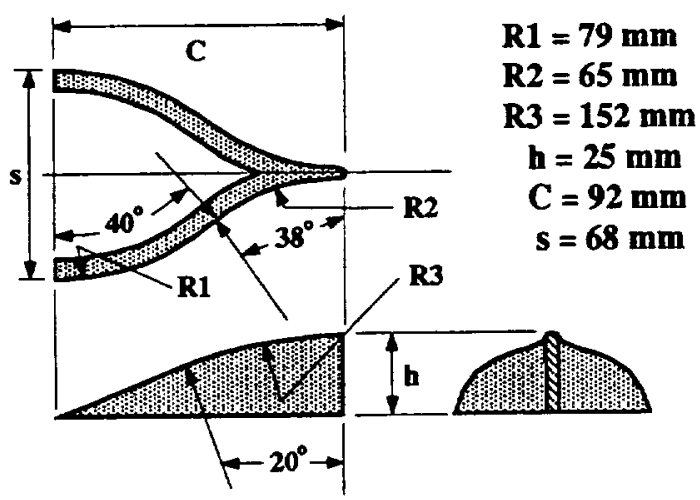

Figure 4 Small wishbone generator geometry. The length dimensions of the larger generator are $\mathbf{2 . 5}$ times the values listed here.

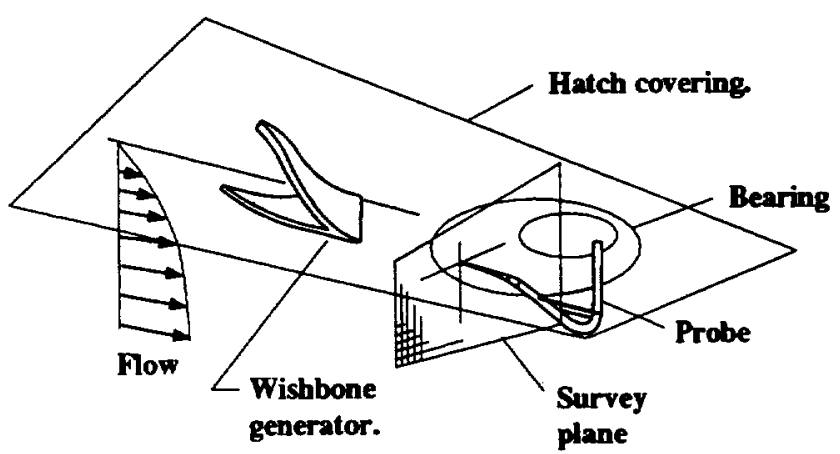

Figure 5 The arrangement of model generator and instrumentation on the test section ceiling.

Right and left side flow symmetry in the crossplane is expected in the wake of the vortex generator. To take advantage of this, the survey grids examined in this study are not centered with respect to the model, but are positioned to favor the right half. The large vortex generator model is mounted with its trailing edge at $(x, z)=(3.24,0.00) \mathrm{m}$. The $15.1 \times 13.5 \mathrm{~cm}(z, y)$ crossplane survey grid used for the larger model is centered at $(x, z)=(3.47,0.04) \mathrm{m}$. This is one chord length downstream of the model.

The smaller vortex generator is mounted at two $x$ locations. The $(x, z)$ trailing edge positions are at $(3.10,0.00) \mathrm{m}$ and $(3.38,0.00) \mathrm{m}$. The axial variation of $\delta$ between these two $x$ positions is negligible. The $11.4 \times 10.8 \mathrm{~cm}$ grid used for the smaller model is centered at $(x, z)=(3.47,0.04) \mathrm{m}$ for survey locations of four chord lengths and one chord length downstream of the model, respectively. The grid spacing for both models is $\Delta z=\Delta y=0.64 \mathrm{cms}$.

\section{Experimental Results}

\section{Small Vortex Generator}

The crossplane velocity field measured one chord length downstream of the small vortex generator $(h / \delta=0.30)$ is shown in Figure 6a. A concentrated pair of upflow vortices is evident in the vector plot.

The three structural descriptors of the RHS vortex are derived from the measured crossplane velocity field illustrated in Figure 6a. The velocity field is first converted to a streamwise vorticity field following the relation:

$$
\omega_{x}=\left(\frac{\delta w}{\delta y}-\frac{\delta v}{\delta z}\right)
$$

Finite difference formulas are used to represent the spatial derivatives in Eq. (1). Figure $6 \mathrm{~b}$ is the vorticity plot corresponding to the velocity field depicted in Figure 6a. $\omega_{i}^{\max }$ is located at a grid point having coordinates $\left(z_{i}, y_{i}\right)$. For the RHS vortex illustrated in Figures 6a-b:

$$
\omega_{i}^{\max }=7586 \mathrm{sec}^{-1}, \quad\left(z_{i}, y_{i}\right)=1.44,2.56 \mathrm{cms} .
$$


The center of the vortex appears to be located on the right shoulder of the vortex generator. The circulation, $\Gamma_{i}$, is calculated by first isolating the region of core vorticity in the data field. This is done by referring to the contour plot in Figure 6b. A path enclosing the region of core vorticity is defined. The circulation is then calculated according to:

$$
\Gamma_{i}=\oint_{\text {path }} \vec{V} \cdot \overrightarrow{d s}
$$

where $\vec{V}$ is the velocity vector in the crossplane, and $\vec{s}$ refers to the path coordinate. By using closed paths

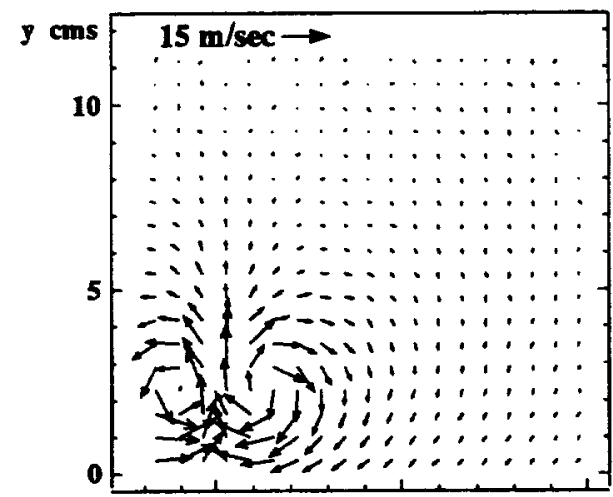

Figure 6a - Transverse velocity.

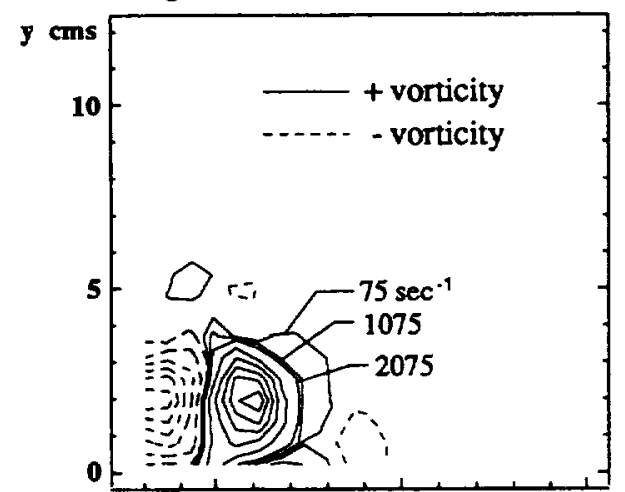

Figure 6b - Streamwise vorticity.

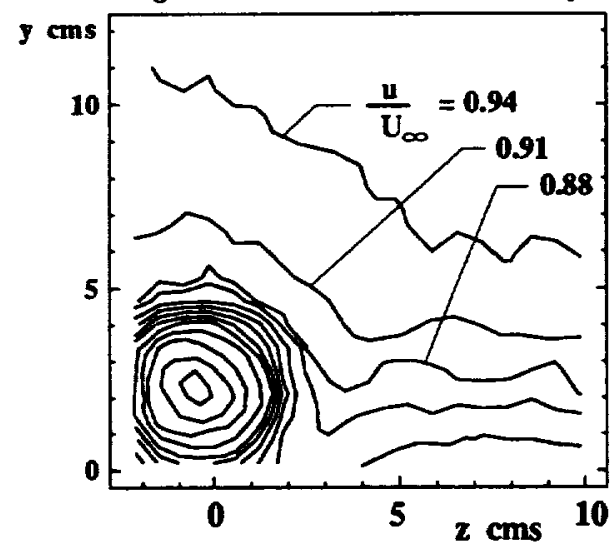

Figure $6 c$ - Primary velocity.

Figure 6 The results one chord length downstream of the small vortex generator. composed of line segments in the $z$ or $y$ coordinate directions, the circulation is easily determined. The circulation of the vortex illustrated in Figure $6 \mathrm{~b}$ is found to be $\Gamma_{i}=1.561 \mathrm{~m}^{2} / \mathrm{sec}$. Contours of streamwise velocity ratio are plotted in Figure $6 c$. The boundary layer is slightly thickened in the vicinity of the embedded upflow pair, as would be expected. An unexpected result is the lack of a streamwise velocity deficit coinciding with the location of each vortex center. A single large region of streamwise velocity deficit encloses both vortex cores and is centered at a crossplane location coincident with the tip location of the vortex generator.

The corresponding results recorded four chord lengths downstream of the small vortex generator are shown in Figures 7a-c. The descriptors of the RHS vortex at this location are:

$$
\begin{gathered}
\omega_{i}^{\max }=1044 \mathrm{sec}^{-1},\left(z_{i}, y_{i}\right)=2.08,5.12 \mathrm{cms}, \\
\Gamma_{i}=1.047 \mathrm{~m}^{2} / \mathrm{sec} .
\end{gathered}
$$

Figures $7 \mathrm{a}$ and $7 \mathrm{c}$ illustrate the displacement of the vortex cores away from the wall, convected there by the strong secondary flows occurring in the upwash region of the vortex pair. As discussed in Wendt et al.," the $33 \%$ reduction in circulation may be attributed, in part, to the crossplane component of wall shear stress which applies a torque opposing the rotation of the vortex. An additional mechanism for the observed circulation decay is the diffusion of vorticity between the closely spaced vortex cores. A steep gradient in streamwise vorticity between the LHS and RHS cores is evident in Figures $6 \mathrm{~b}$ and $7 \mathrm{~b}$. In addition to reducing circulation and peak vorticity, diffusion of the core vorticity has significantly increased the core size as can be seen by comparing Figures 6 and 7. Located under the core in Figure $7 \mathrm{~b}$ is a region of "secondary" vorticity. This vorticity, opposite in sign to that of the core or "primary" vorticity, is induced by the viscous interaction between the secondary flows of the vortex and the wall. Figure $7 \mathrm{c}$ again shows a single region of streamwise velocity deficit. This region is now centered between, and above, the vortex cores.

\section{Large Vortex Generator}

The results obtained one chord length downstream of the large vortex generator $(h / \delta=0.70)$ are illustrated in Figures 8a-c. The descriptors of the RHS vortex are:

$$
\begin{gathered}
\omega_{i}^{\max }=6435 \mathrm{sec}^{-1},\left(z_{i}, y_{i}\right)=2.74,8.15 \mathrm{cms}, \\
\Gamma_{i}=5.173 \mathrm{~m}^{2} / \mathrm{sec} .
\end{gathered}
$$

\section{Modeling}

The large number of parameters to consider when designing a vortex generator array for an aircraft component, such as a wing or inlet, has the implication that 
experimental work on optimum designs is often slow and expensive. This fact has motivated a few workers in computational fluid mechanics to assist in the optimizing problem by including a means of representing vortex generators in their codes. A simple and effective means of doing this is to employ a model for the crossplane velocity or vorticity induced by the generators. This is the approach taken in recent work by Anderson et al. ${ }^{10,11}$ who examined multiple vortex generator array geometries in a diffusing S-duct inlet using a parabolized Navier-Stokes (RNS) solver. A similar inclusion of embedded vortices in a full Navier-Stokes (FNS) code was implemented by

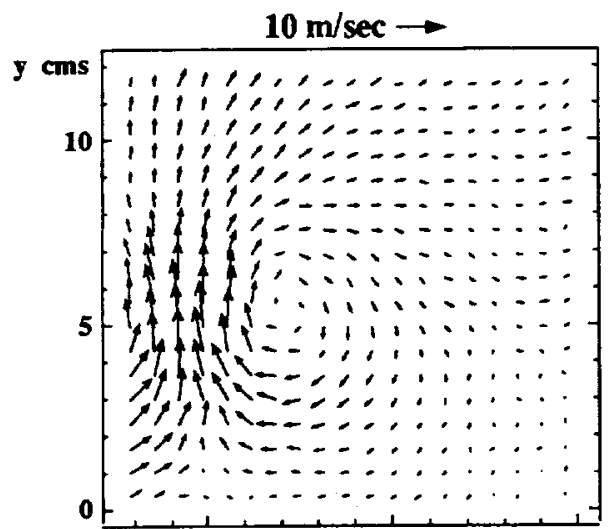

Figure 7a - Transverse velocity.

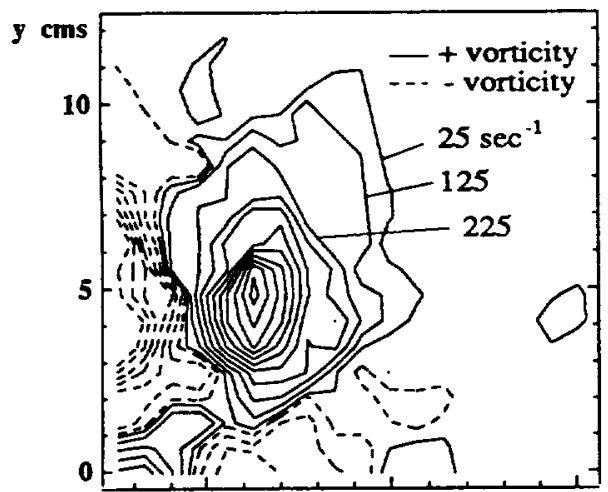

Figure $7 \mathrm{~b}$ - Stream wise vorticity.

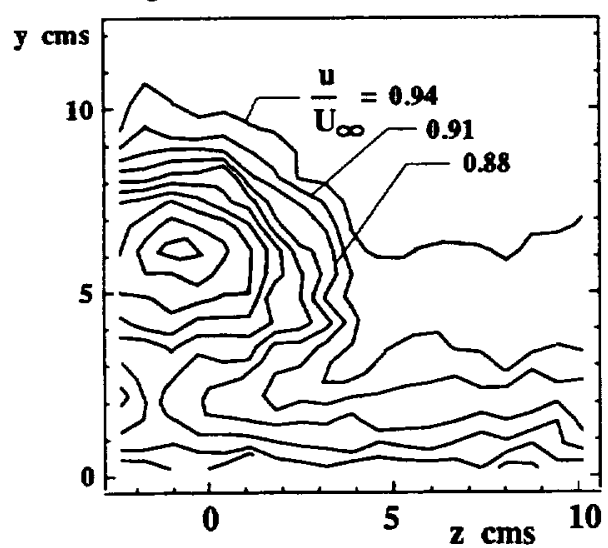

Figure 7c $\cdot$ Primary velocity.

Figure 7 The results obtained four chord lengths downstream of the small vortex generator.

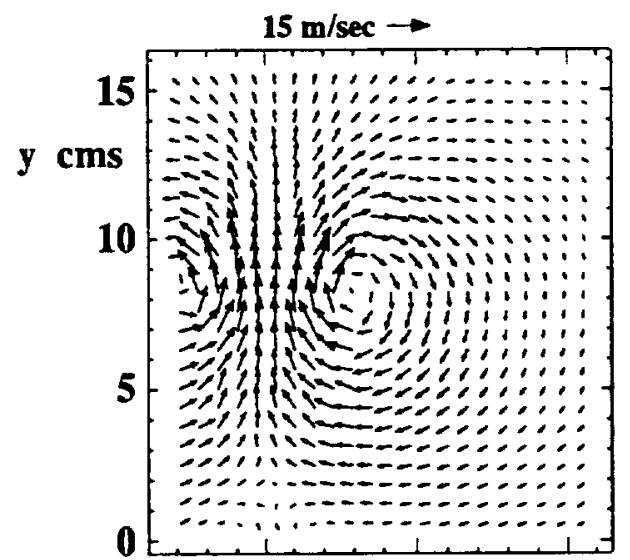

Figure 8a - Transverse velocity.

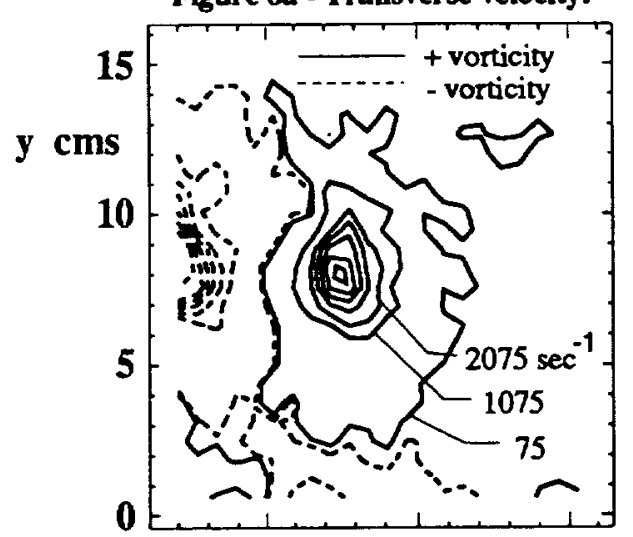

Figure 8b - Streamwise vorticity.

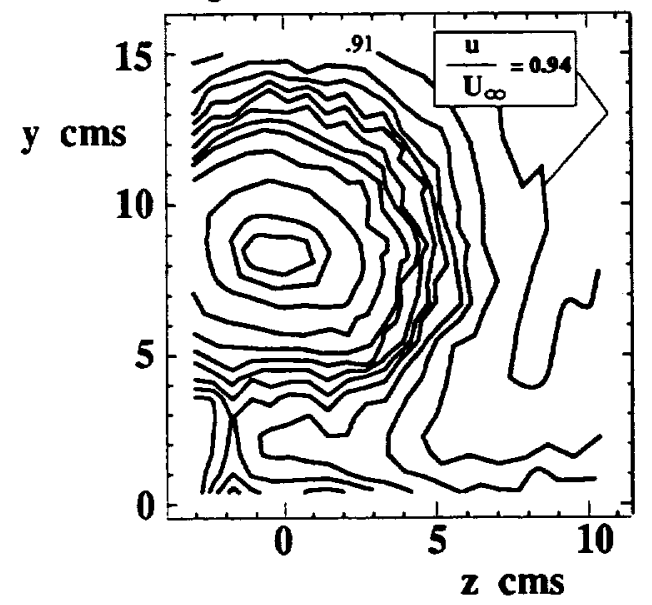

Figure 8c - Primary velocity.

Figure 8 The results obtained one chord length downstream of the large vortex generator.

Cho and Greber ${ }^{12}$ for a constant area circular duct and a diffusing S-duct geometry. The advantage of this approach lies in the fact that a newly formed vortex may be accurately represented in this manner.

Experimental workers concerned with embedded vortices have often noticed the close similarity of observed crossplane vortex structure to simple twodimensional models of vortices. Inviscid or "potential" models were first applied to results obtained in subsonic diffusers by Taylor and Grose. ${ }^{13}$ Later, Pearcy ${ }^{14}$ would 
develop embedded vortex interaction models based on the inviscid representation of embedded vortex structure. Eibeck and Eaton ${ }^{15}$ compared the structure of a single embedded vortex to that of the patchwork "Rankine" model vortex. Studies by Pauley and Eaton ${ }^{16}$ and Wendt et al. ${ }^{17}$ have made comparisons to the "ideal viscous" or "Oseen" model.

Lets now examine the equations of the Oseen model and show the comparison between the model and the present results.

\section{The Oseen Model of the Embedded Vortex}

The two-dimensional Oseen model of a viscous vortex represents the time dependent decay of a potential vortex where the velocity at the origin $(r=0)$ is forced to zero at time $t=0$. A single isolated vortex centered on the crossplane origin has velocity components (in cylindrical coordinates):

$$
\begin{gathered}
v_{r}=0, \\
v_{\theta}=\frac{\Gamma}{2 \pi r}\left(1-\mathrm{e}^{r^{\vartheta} /(4 \nu t)}\right),
\end{gathered}
$$

where $\Gamma$ is the vortex circulation and $\nu$ the laminar coefficient of kinematic viscosity. Following Squire ${ }^{18}$ the unsteady solution is transformed to a steady one by relating the decay time to the distance between the vortex generator tip and the crossplane of interest $\left(x-x_{0}\right)$ :

$$
t \approx \frac{x-x_{0}}{U_{\infty}}
$$

For an isolated turbulent vortex $i$ located at $\left(z_{i}, y_{i}\right)$ the velocity components in the crossplane can be written in terms of the vortex descriptors. ${ }^{17}$ In cartesian coordinates:

$$
\begin{gathered}
v_{i}=\frac{\Gamma_{i}\left(z-z_{i}\right)}{2 \pi R_{i}^{2}} F_{i}, \\
w_{i}=-\frac{\Gamma_{i}\left(y-y_{i}\right)}{2 \pi R_{i}^{2}} F_{i},
\end{gathered}
$$

where:

$$
R_{i}^{2}=\left(z-z_{i}\right)^{2}+\left(y-y_{i}\right)^{2},
$$

and:

$$
F_{i}=1-\exp \left\{-\frac{\pi \omega_{i}^{\max }}{\Gamma_{i}} R_{i}^{2}\right\}
$$

The vorticity field is given by:

$$
\omega_{i}^{x}=\omega_{i}^{\max }\left(1-F_{i}\right)
$$

We can superimpose solutions for a representation of the wall and neighboring vortices. Figure 9 illustrates how a representation of a single embedded vortex is constructed. Eqs. (8) represent the secondary velocities

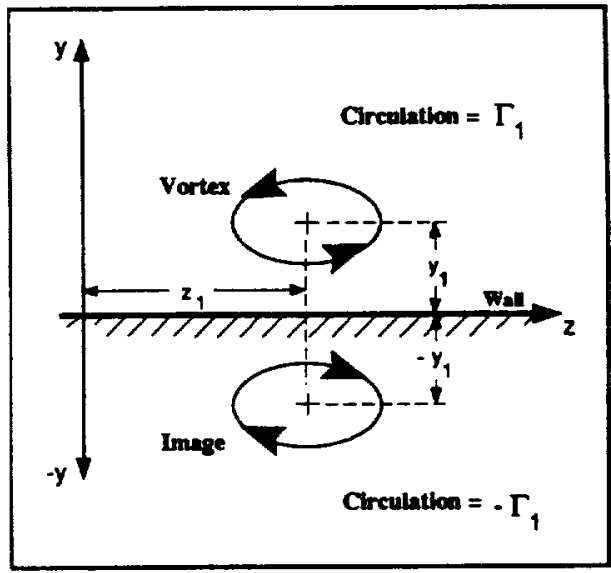

Figure 9 The construction of an Oseen model of a single embedded vortex.

$v_{i}$ and $w_{i}$ for the vortex above the wall. The equations for the image vortex are identical except for the sign switch on $\Gamma_{i}$ and $y_{i}$. Denote these velocities $v_{i m i}$ and $w_{i m i}$. The equations representing the embedded vortex are then simply:

$$
\begin{gathered}
v=v_{1}+v_{i m 1}, \\
w=w_{1}+w_{i m 1} .
\end{gathered}
$$

Figure 10 illustrates the construction of an embedded array of $N$ vortices. The secondary velocities of this

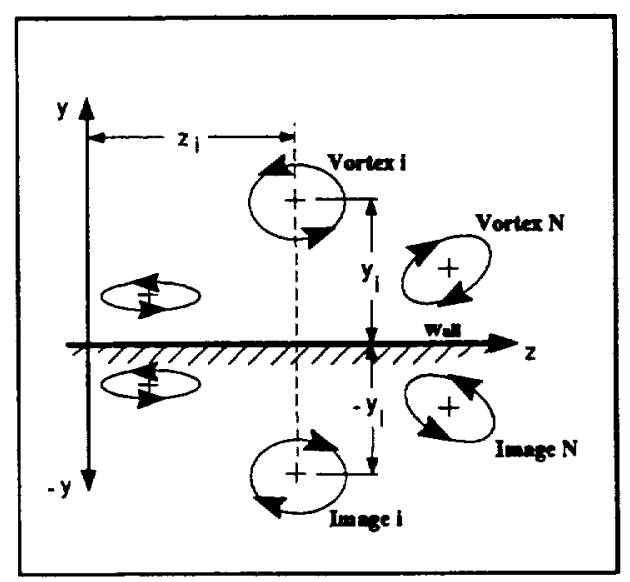

Figure 10 The construction of an Oseen model of an array of $\mathbf{N}$ embedded vorticies.

flow field are:

$$
\begin{gathered}
v=v_{1}+v_{i m 1}+v_{2}+v_{i m 2}+\cdots \\
\cdots+v_{N}+v_{i m N} \\
w=w_{1}+w_{i m 1}+w_{2}+w_{i m 2}+\cdots \\
\cdots+w_{N}+w_{i m N}
\end{gathered}
$$




\section{Model and Data Comparisons}

The model is constructed by matching the vortex descriptors in the equations to those previously listed for the data (Eqs. 2, 4, and 5). The circulation and peak vorticity descriptors for the LHS vortex in each case are chosen to be equal (but opposite in sign) to the descriptor values determined for the RHS vortex. $\left(z_{i}, y_{i}\right)$ for the LHS vortex is found by symmetry with respect to the line $(x, y=0, z=0)$.

Figure 11a illustrates the crossplane velocity field of the model when the vortex descriptors are matched to those obtained from the data taken one chord length downstream of the small vortex generator. This can be

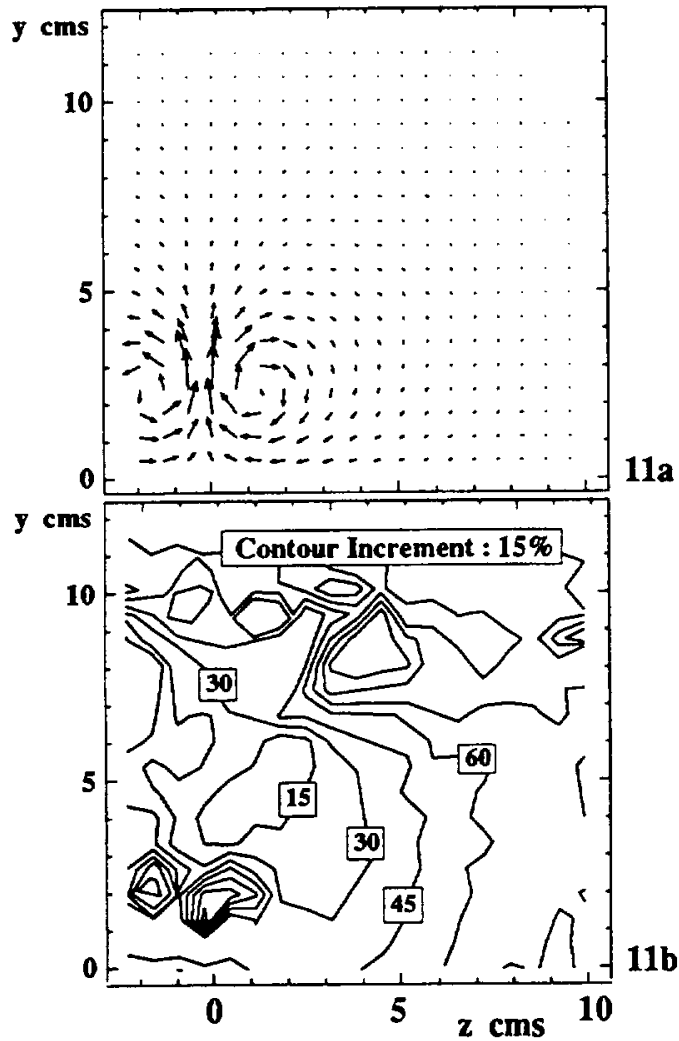

Figure 11 The model velocity field (11a) one chord length downstream of the small vortex generator, and a contour plot of the variance between the measured velocities and the model (11b).

compared to Figure 6a. One point to note is that the near wall velocities are a good deal weaker in the model representation of the data. Figure $11 \mathrm{~b}$ is a contour plot of the variance between the data and the model defined as:

$$
\text { variance }=\frac{\left\|\vec{V}_{\text {data }}-\vec{V}_{\text {model }}\right\|}{\left\|\vec{V}_{\text {data }}\right\|} \text {. }
$$

The best comparison occurs just above the RHS core, where the variance is less than $15 \%$.

Figures 12a-b illustrate the corresponding results for the crossplane field four chord lengths downstream of the

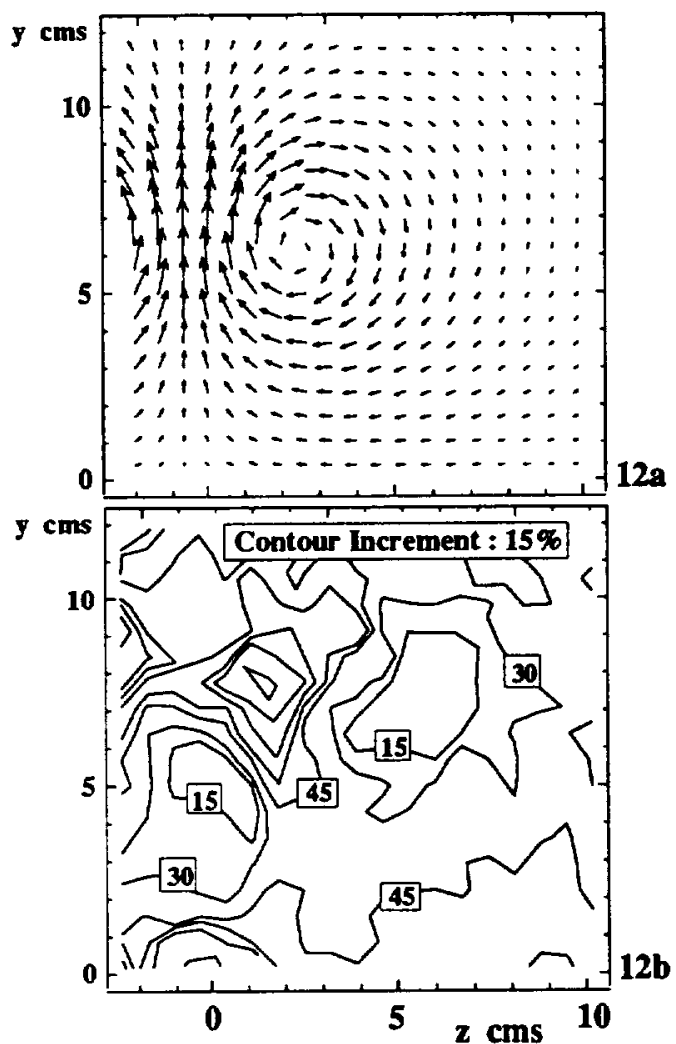

Figure 12 The model velocity field (12a) four chord lengths downstream of the small vortex generator, and a contour plot of the variance between the measured velocities and the model (12b).

small vortex generator. Figure 12a may be compared to Figure 7a. The best comparison here occurs just below the vortex core, and to either side.

Figures 13a-b illustrate the model and variance obtained one chord length downstream of the large vortex generator. Figure 13a may be compared to Figure 8a. The model provides a better match to the data in this case, as evidenced by the large regions of the flow field (in the vortex upwash, downwash, and above the core) where the variance is less than $15 \%$.

\section{Summary}

The low profile wishbone generator sheds a strong pair of counter-rotating vortices. Measurements of velocity in a downstream crossplane form the basis for characterization of the vortex structures. Vortex structure was quantified by three descriptors. Vortex strength was characterized by its circulation or integrated streamwise vorticity, vortex concentration by the magnitude of peak vorticity, and the vortex trajectory by the location of peak vorticity.

Measurements made at two axial locations illustrate the streamwise development of the shed vortices. The counter-rotating pair of vortices was observed to lift off 


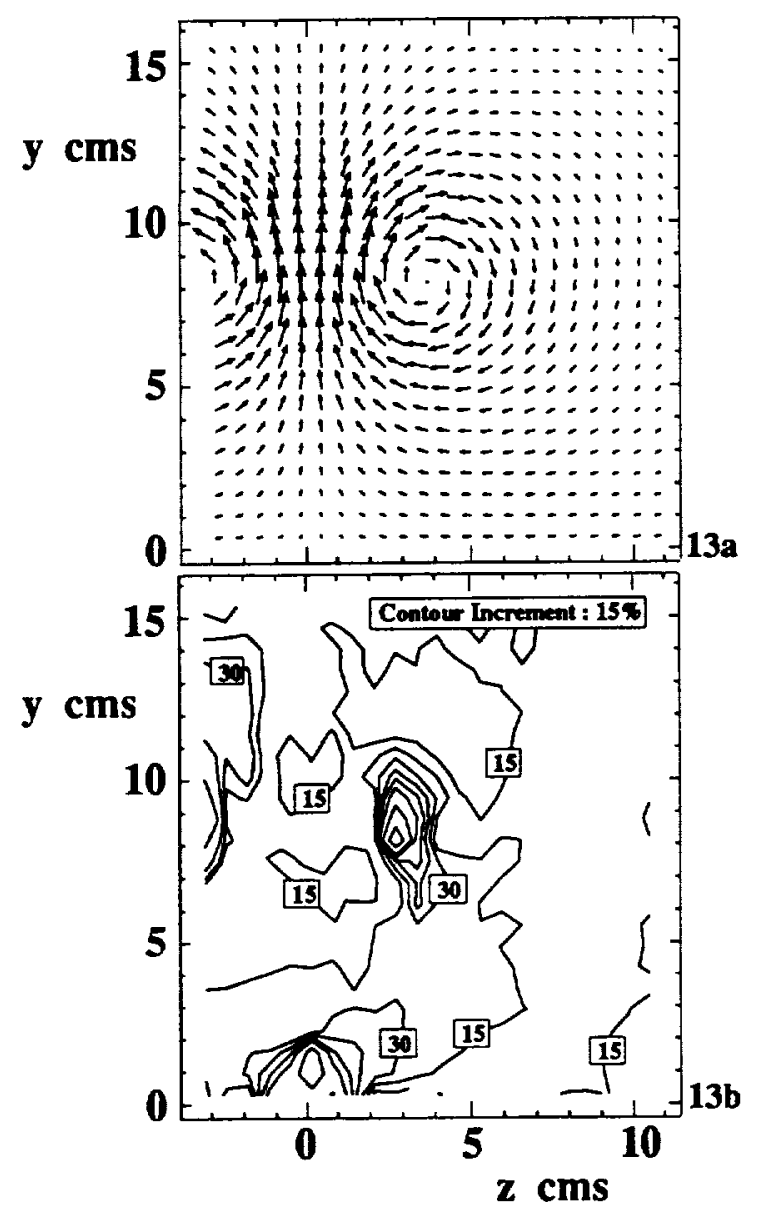

Figure 13 The model velocity field (13a) one chord length downstream of the large vortex generator, and a contour plot of the variance between the measured velocities and the model (13b).

the surface quickly. A single region of streamwise velocity deficit was located between vortex cores. Although the observed three-dimensional flow structure was complex, the flow in the crossplane is well represented by the two-dimensional Oseen model, particularly in the case of the larger vortex generator.

\section{Acknowledgements}

The authors are indebted to the project support provided by David Sheldon and Victor Canacci, operation engineers for NASA's Aeropropulsion Facilities and Experiments Division; and the rest of the very capable staff of the Icing Research Tunnel. Also, a special thank you to Dr. Bruce Reichert, of NASA's Intemal Fluid Mechanics Division, for his insightful analysis of the data.

\section{References}

${ }^{1}$ Dunne, A. L., Black, S., Schmidt, G. S., and Lewis, T. L., "VLA Missile Development and High Angle of
Attack Behavior," Loral Defense Systems tech. rep., Nov. 1988.

${ }^{2}$ McCormick, D. C., "Shock-Boundary Layer Interaction Control with Low Profile Vortex Generators and Passive Cavity," AIAA Paper 92-0064, Jan. 1992.

${ }^{3}$ Reichert, B. A. and Wendt, B. J., "An Experimental Investigation of S-Duct Flow Control Using Arrays of Low Profile Vortex Generators," AIAA Paper 93-0018, Jan. 1993.

${ }^{4}$ Lin, J. C., Howard, F. G., and Selby, G. V., "Turbulent Flow Seperation Control Through Passive Techniques," AIAA Paper 89-0976, Mar. 1990.

${ }^{5}$ Wendt, B. J., Greber, I., and Hingst, W. R., "The Structure and Development of Streamwise Vortex Arrays Embedded in a Turbulent Boundary Layer," AIAA Journal, Vol. 31, Feb. 1993, pp. 319-325.

${ }^{6}$ Soeder, R. H. and Andracchio, C. R., "NASA Lewis Icing Research Tunnel User Manual, NASA TM 102319, June 1990.

${ }^{7}$ Wheeler, G. O., "Means for Maintaining Attached Flow of a Flowing Medium," United States Patent 4,455,045 , June, 1984.

${ }^{8}$ Treaster, A. L. and Yocum, A. M., "The Calibration and Application of Five-Hole Probes," ISA Transactions, Vol. 18, 1979, pp. 23-34.

${ }^{9}$ Wendt, B. J., Greber, I., and Hingst, W. R., "The Structure and Development of Streamwise Vortex Arrays Embedded in a Turbulent Boundary Layer," AIAA Paper 92-0551, Jan. 1992.

${ }^{10}$ Anderson, B. H. and Farokhi, S., "A Study of Three Dimensional Turbulent Boundary Layer Separation and Vortex Flow Control Using the Reduced Navier-Stokes Equations," Turbulent Shear Flow Symposium tech. rep., 1991.

${ }^{11}$ Anderson, B. H. and Gibb, J., "Application of Computational Fluid Dynamics to the Study of Vortex Flow Control for the Management of Inlet Distortion," AIAA Paper 92-3177, July 1992.

${ }^{12}$ Cho, S. Y. and Greber, I., Three Dimensional Compressible Turbulent Flow Computations for a Diffusing S-Duct With/Without Vortex Generators, Ph.D. Dissertation, Case Western Reserve University, Nov. 1992.

${ }^{13}$ Taylor, H. D. and Grose, R. M., "Theoretical and Experimental Investigation of Various Types of Vortex Generators," United Aircraft Corporation Research Department Report R-15362-5, 1954.

${ }^{14}$ Pearcy, H. H., "Shock-Induced Separation and its Prevention by Design and Boundary Layer Control," Boundary Layer and Flow Control, Vol. 4, edited by G. V. Lachmann, 1961.

${ }^{15}$ Eibeck, P. A. and Eaton, J. K., "An Experimental Investigation of the Heat-Transfer Effects of a Longitudinal Vortex Embedded in a Turbulent Boundary Layer," Stanford University Tech. Rep. MD-48, 1985. 
${ }^{16}$ Pauley, W. R. and Eaton, J. K., "The Fluid Dynamics and Heat Transfer Effects of Streamwise Vortices Embedded in a Turbulent Boundary Layer," Stanford University Tech. Rep. MD-51, 1988.

${ }^{17}$ Wendt, B. J., Greber, I., and Hingst, W. R., "The Structure and Development of Streamwise Vortex Arrays
Embedded in a Turbulent Boundary Layer," NASA TM $105211,1991$.

${ }^{18}$ Squire, H. H., "The Growth of a Vortex in Turbulent Flow," Aeronautical Quarterly, Vol. 16, 1965, pp. 302306. 


\begin{tabular}{|c|c|c|}
\hline \multicolumn{2}{|c|}{ REPORT DOCUMENTATION PAGE } & $\begin{array}{l}\text { Form Approved } \\
\text { OMB No. 0704-0188 }\end{array}$ \\
\hline \multicolumn{3}{|c|}{ 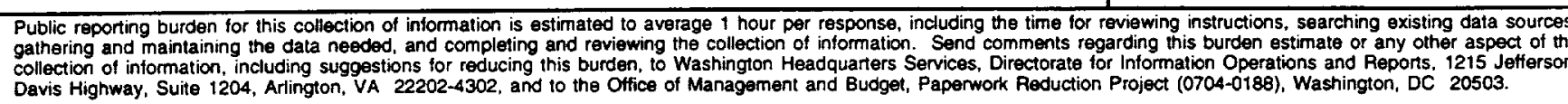 } \\
\hline 1. AGENCY USE ONLY (Leave blank) & \begin{tabular}{|c|c|}
$\begin{array}{c}\text { 2. REPORT DATE } \\
\text { January } 1994\end{array}$ & 3. \\
\end{tabular} & $\begin{array}{l}\text { 3. AEPORT TYPE AND DATES COVERED } \\
\text { Technical Memorandum }\end{array}$ \\
\hline \multicolumn{2}{|c|}{$\begin{array}{l}\text { 4. TITLE AND SUBTITLE } \\
\text { Measurements and Modeling of Flow Structure in the Wake of a } \\
\text { Low Profile "Wishbone" Vortex Generator }\end{array}$} & \multirow{2}{*}{$\begin{array}{l}\text { 5. FUNDING NUMBERS } \\
\text { WU-505-62-52 }\end{array}$} \\
\hline \multicolumn{2}{|l|}{ 6. AUTHOR(S) } & \\
\hline \multicolumn{2}{|c|}{$\begin{array}{l}\text { National Aeronautics and Space Administration } \\
\text { Lewis Research Center } \\
\text { Cleveland, Ohio } 44135-3191\end{array}$} & $\begin{array}{l}\text { 8. PERFORMING ORGANIZATION } \\
\text { REPORT NUMBER } \\
\text { E-8334 }\end{array}$ \\
\hline \multicolumn{2}{|c|}{$\begin{array}{l}\text { National Aeronautics and Space Administration } \\
\text { Washington, D.C. } 20546-0001\end{array}$} & $\begin{array}{l}\text { 10. SPONSORING/MONITORING } \\
\text { AGENCY REPORT NUMBER } \\
\text { NASA TM-106468 } \\
\text { AIAA-94-0620 }\end{array}$ \\
\hline \multicolumn{3}{|c|}{$\begin{array}{l}\text { 11. SUPPLEMENTARY NOTES } \\
\text { Prepared for the AIAA 32nd Aerospace Sciences Meeting and Exhibit sponsored by the American Institute of Aeronautics and } \\
\text { Astronautics, Reno, Nevada, January 10-13, 1994. B.J. Wendt, National Research Council and NASA Research Associate at } \\
\text { Lewis Research Center; and W.R. Hingst, Lewis Research Center, Cleveland, Ohio. Responsible person, B.J. Wendt; Inlet, Duct } \\
\text { and Nozzle Flow Physics Branch 2660, (216) 433-5906. }\end{array}$} \\
\hline \multicolumn{2}{|c|}{$\begin{array}{l}\text { 12a. DISTRIBUTIONAVAILABILITY STATEMENT } \\
\text { Unclassified - Unlimited } \\
\text { Subject Category } 02 \text { and } 34\end{array}$} & 12b. DISTRIBUTION CODE \\
\hline
\end{tabular}

\section{ABSTRACT (Maximum 200 words)}

The results of an experimental examination of the vortex structures shed from a low profile "wishbone" generator are presented. The vortex generator height relative to the turbulent boundary layer was varied by testing two differently sized models. Measurements of the mean three-dimensional velocity field were conducted in cross-stream planes downstream of the vortex generators. In all cases a counter-rotating vortex pair was observed. Individual vortices were characterized by three descriptors derived from the velocity data; circulation, peak vorticity, and cross-stream location of peak vorticity. Measurements in the crossplane at two axial locations behind the smaller wishbone characterize the downstream development of the vortex pairs. A single region of streamwise velocity deficit is shared by both vortex cores. This is in contrast to conventional generators, where each core coincides with a region of velocity deficit. The measured cross-stream velocities for each case are compared to an Oseen model with matching descriptors. The best comparison occurs with the data from the larger wishbone.

\section{SUBJECT TERMS}

Embedded vortices; Wishbone vortex generator; Oseen model

\begin{tabular}{|c|c|}
\hline $\begin{array}{c}\text { 17. SECURITY CLASSIFICATION } \\
\text { OF REPORT } \\
\text { Unclassified }\end{array}$ & $\begin{array}{c}\text { 18. SECURITY CLASSIFICATION } \\
\text { OF THIS PAGE } \\
\text { Unclassified }\end{array}$ \\
\hline
\end{tabular}

NSN 7540-01-280-5500
19. SECURITY CLASSIFICATION OF ABSTRACT Unclassified 